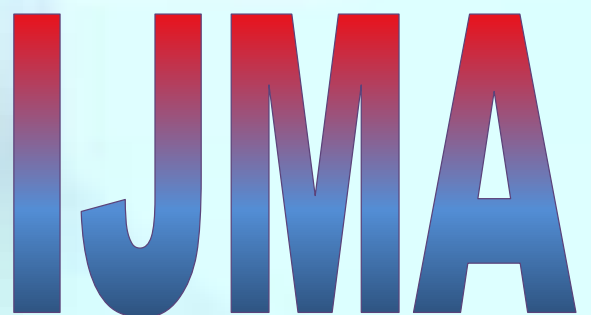

INTERNATIONAL

Journal of MEdical

\section{ARTS}

Volume 3, Issue 1 (Winter 2021)

http://ijma.journals.ekb.eg/

Print ISSN: 2636-4174

Online ISSN: 2682-3780

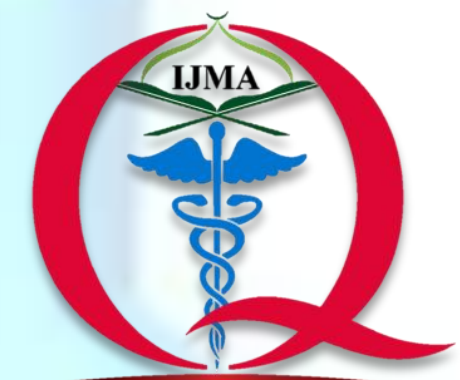

International Jounnal of Medical Arts

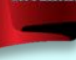




\section{About IJMA}

- International Journal of Medical Arts is the Official Journal of the Damietta Faculty of Medicine, Al-Azhar University, Egypt

- The First Issue was published in July 2019

- It is an International, Open Access, Double-blind, Peerreviewed Journal

- Published four times a year

- Published under the following license: Creative Commons Attribution-ShareAlike 4.0 International Public License (CC BY-SA 4.0). It had updated from the Creative Commons license [CC BY] in volume 2, Issue 4, October 2020

- The Egyptian Knowledge Bank hosts the web site of IJMA

- The Egyptian Knowledge Bank supports IJMA

- IJMA is indexed in the "Directory of Open Access Journals" Indexed on 15 January 2021.

- IJMA follows the regulations of the International Committee of Medical Journal Editors (list date 1/21/20)

- IJMA is a member of The International Society of Managing and Technical Editors

- IJMA is listed in Index Copernicus

- IJMA is listed in Publons, as EKB is an official partner with Clarivate Analytics
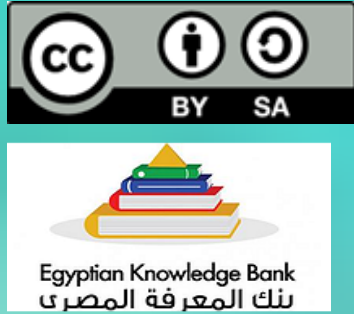

\section{DOAJ}

CMNE

ISMTE

INDEX COPERNICUS

publons 
International Journal of Medical Arts 2021; 3 [1]: 1069-1074.

Available online at Journal Website
https://ijma.journals.ekb.eg/
Main subject [Otorhinolaryngology]

Original article

\title{
The Value of Endoscopic Dacryocystorhinostomy in Management of Acquired Nasolacrimal Duct Obstruction
}

\author{
Ahmed Sobhi Abdelaal[1]; Ahmed Ibrahim Zaghloul[2]
}

Department of Otorhinolaryngology, Faculty of Medicine, Al-Azhar University, Egypt[1].

Department of Otorhinolaryngology, Damietta Faculty of Medicine, Al-Azhar University, Egypt[2].

Corresponding author: Ahmed Sobhi Abdelaal

Email: dr_ahmedsobhi84@yahoo.com

Received at: September 14, 2020; Revised at: November 02, 2020; Accepted at: Nobember 11, 2020

DOI: 10.21608/ijma.2020.42826.1169

ABSTRACT

Background: The epiphora is the most common manifestation of obstruction of the nasolacrimal duct, which is treated by dacryocystorhinostomy either by external or internal endoscopic endonasal approach. With the advance of the nasal endoscope, the endoscopic dacryocystorhinostomy became well established.

Aim of the work: To evaluate the efficacy and safety of intranasal endoscopic dacryocystorhinostomy [DCR] in the management of patients with acquired nasolacrimal duct obstruction.

Patients and Methods: This is a retrospective study of patients with acquired obstruction of the nasolacrimal duct who underwent intra-nasal endoscopic dacryocystorhinostomy [EDCR] at Al-Azhar University Hospitals from September 2012 to October 2015. Forty-five procedures were done where primary endoscopic DCR was done on forty patients and revision endoscopic DCR was done on failed five patients. The outcome is measured by subjective improvement of epiphora.

Results: The patients were followed up for three years, improvement of 35 patients with epiphora from 40 patients [the rate of success was $86.7 \%$ ] and the remaining five failed cases undergoing revision EDCR with the improvement of four from them. The success was confirmed with the subjective improvement of epiphora. The rate of minor complications reported was $28.8 \%$ and managed conservative, and only one major complication occurred in one patient.

Conclusion: The endoscopic intranasal DCR is an effective and safe procedure in the management of acquired obstruction of the nasolacrimal duct and gives a high success rate.

Keywords: Endoscopic; Endonasal; Dacryocystorhinostomy; Nasolacrimal duct; Epiphora.

This is an open-access article registered under the Creative Commons, ShareAlike 4.0 International license [CC BY-SA 4.0] [https://creativecommons.org/licenses/by-sa/4.0/legalcode.

Please cite this article: Abdelaal AS, Zaghloul Al. The Value of Endoscopic Dacryocystorhinostomy in Management of Acquired Nasolacrimal Duct Obstruction. IJMA 2021; 3[1]: 1069-1074. DOI: 10.21608/ijma.2020.42826.1169

* Main subject and any subcategories have been classified according to the research topic. 


\section{INTRODUCTION}

Dacryocystorhinostomy is the creation of the functional pathway for the lacrimal canaliculi to the nose by doing osteotomy and opening the nasolacrimal sac into the nose, and this is performed by either external or endonasal approach [1]. The lacrimal system obstruction is manifested by continuous watery eyes with sometimes an attack of lacrimal sac swelling and redness in chronic dacryocystitis. The main treatment of this disease was an external approach, but the intra- nasal dacryocystorhinostomy approach was first described by Caldwell in 1983, which is used nowadays[ 2-3|. Obstruction of the lacrimal system may be congenital or acquired, the acquired caused by chronic inflammation causing fibrosis, stenosis with closure of the ostium of the lacrimal duct ${ }^{|4|}$. The lacrimal system obstruction can be solved by making fistula between the lacrimal and nasal mucosa to by-pass the obstruction and maintain the tear flow ${ }^{[5]}$.The external endoscopic DCR was the traditional management for acquired obstruction of nasolacrimal duct in the past, even after endoscopic DCR is discovered because of limited technology and success rate $80 \%-100 \%[5]$. As a result of advances in endoscopic evaluation, the presence of new rhino logic instruments and unique experience increases the rate of success of EDCR over external approach ${ }^{[6,7]}$.Although E DCR has several techniques, the most successful one is the powered instrumentation with preservation of mucosal flap the powered EDCR is first developed by Wormald in 2002 ${ }^{[8]}$. Subsequently, published reports have proved the efficacy of EDCR ${ }^{[9]}$. The disadvantages of the external approach of DCR are external scar, the possibility of injury of the ligament of medial canthus, immediate post-operative morbidity as epistaxis and periorbital ecchymosis, delayed postoperative morbidity as the development of sinusitis, and intra-nasal crusting ${ }^{[101}$. Advantages of EDCR: no external scar, preservation of lacrimal pumping system, short recovery time, and low postoperative morbidity ${ }^{1111}$.

\section{AIM OF THE WORK}

The study is designed to evaluate the advantages of endonasal EDCR in managing patients with acquired obstruction of the nasolacrimal duct.

\section{PATIENTS AND METHODS}

This is a retrospective study of 45 patients. Forty primary EDCR and five revision EDCR were done from September 2012 to October 2015 who acquired the nasolacrimal duct's obstruction. All the operations were done in Al Azahr university hospitals. The local ethics and research committee approved the research protocol, and an informed consent was taken from all patients after explaining the procedure.

Inclusion criteria were: patients with acquired nasolacrimal duct or lacrimal sac obstruction, patients with post-traumatic epiphora, canillicular obstruction, and primary neoplasm of lacrimal system. However, congenital cases were excluded.

All operations were done under general anesthesia, any underlying sinonasal pathology as septal deviation and middle turbinate deformity is corrected with the surgery. The surgery begins with the patient in anti-trendelenbeg position with hypotensive anesthesia, instillation of local anesthesia and vasoconstriction [ $\%$ lidocaine and $1 \mathrm{mg}$ adrenaline diluted in $200 \mathrm{cc}$ saline] into upper anterior part of the lateral wall of the nose; a rectangular incision was done with sickle knife at the level of the upper end of attachment middle turbinate with the lateral wall of the nose anterior to the maxillary line, the incised mucosa is lifted with freer elevator, removal of the bone over the lacrimal protuberance with mico-drill [corresponding to the medial bony half of the lacrimal sac]. Through the caniliculus, the probe is inserted tenting the membranous medial wall of the lacrimal sac, in which the probe is seen with the nasal endoscope; the medial wall of the lacrimal sac was identified, excised with sickle knife and removed with a Blakesley forceps or placed as inferior flap .Insertion of silicone tube into each caniliculus down to the lacrimal sac which dragged into the nasal cavity and sutured together with multiple knots which is secured. The blood clots and secretions are removed at the end of operation. Broad spectrum antibiotic and topical antibiotic were prescribed .Nasal packing is inserted if septoplasty was done with the operation and removed after 48 hours. Irrigation the nasal cavity 4 to5 times with saline per day for 2 weeks to remove any blood crusting and promote mucosal healing. 


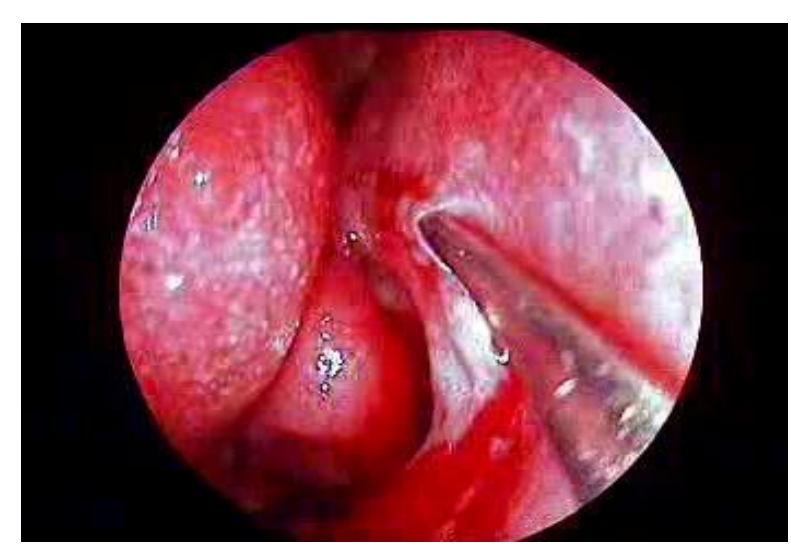

Figure [1]: Incision with the sickle knife of the lateral nasal wall at the upper end of attachment of the middle turbinate anterior to the maxillary line.

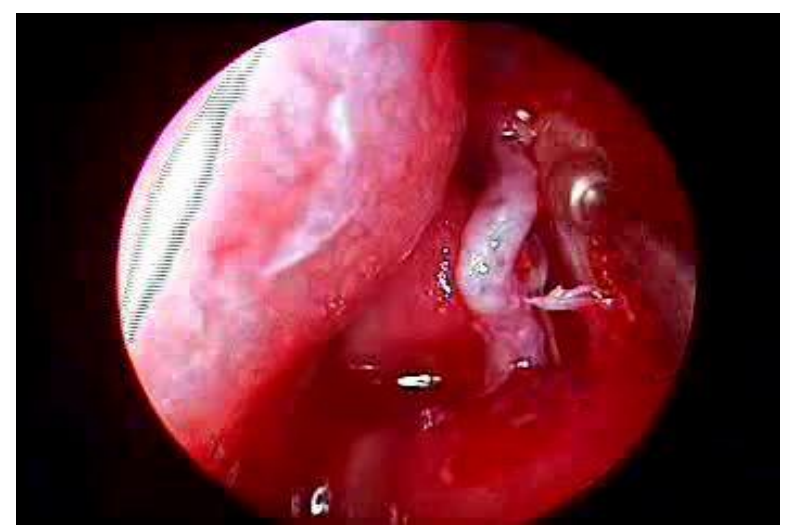

Figure [2]: Drilling of the lacrimal protuberance bone over the lacrimal sac with micro-drill.

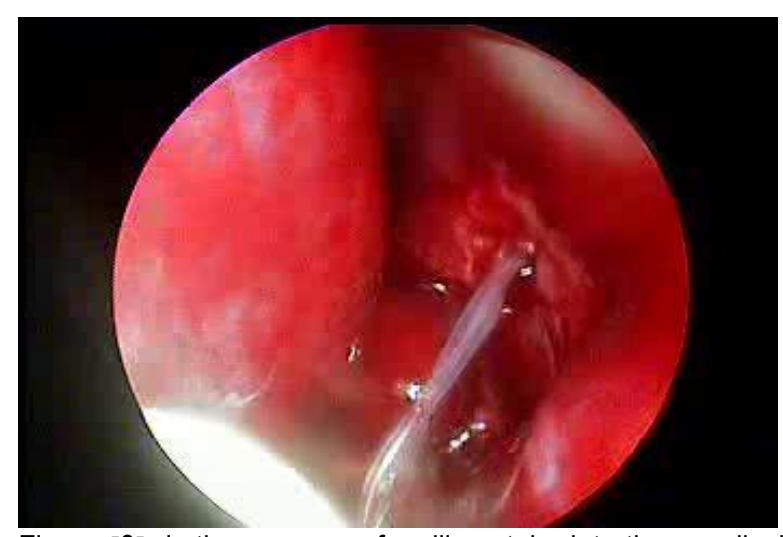

Figure [3]: is the passage of a silicon tube into the canaliculi and secured into the nasal cavity with multiple knots with the aid of an endoscope.

The patient is seen after one and two weeks postoperative to remove any dried blood clots and crusts in the ear, nose, and throat [ENT] office. Topical eye drops and nasal irrigation is started on the first post-operative day. Silicone tube is removed from the nasal cavity after cutting it at the medial canthus without any complications. The silicone tube is removed within 2-6 months. The patients were followed up for the subjective improvement of epiphora.

Data analysis: The collected data had been coded and fed to a personal computer, Categorical data presented in the form of frequencies and percentages, while mean and standard deviation calculated for presentation for numerical data. Groups compared by [t] or Chi-square tests according to data types. $\mathrm{P}<0.05$ had been considered significant. The SPSS version 18 [SPSS Inc., Chicago, USA] had been used to calculate all statistical processes.

\section{RESULTS}

A total of 45 EDCR were performed on 40 patients where the mean age in succeeded patients is 37.49 and SD is 12.3 , the mean age in failed patients is 37 and SD is 11.8, as shown in table [1]. 29 female 26 of them succeeded, and three failed, 16 male 13 of them succeeded and 3 failed as shown in table [1]. The succeeded patients in primary EDCR were 35 from 40 patients and 4 from 5 patients in revision EDCR. The average follow up of post -operative patients was 3-24 months. The rate of success was $86.7 \%$ and the failure rate were occurred in 5 endoscopic DCR $13.3 \%$.The failed 5 eyes undergoing revision endoscopic DCR, and four eyes were improved as presented in table [1]. There are minor intra and post -operative complications among all primary and revision EDCR occurred in 13 patients and managed conservative without interference where itra nasal synechia occurred in 5 patients, eye and check bruises in 6 patients, stent fallen out in 3 patients, 4 patients with nostril burn and intranasal synechia with the stent fallen out in one patient in revision operations as presented in table [2]. Only one major complication which is orbital penetration, with orbital fat exposure was occurred in one patient in primary EDCR and didn't occur in revision EDCR as as presented in table [2]. The failure has occurred as a result of post- operative scar at the operation site ,associated septal deviation, neo bone formation with osteogenesis, failure in locating the lacrimal sac, and intra nasal synechia, which was corrected in the revision surgery where septoplasty ,release and cut of intra nasal synechia were done with good results as presented in table [3].

The deviated septum was present in 6 patients and corrected where septoplasty done in 5 patients 
with primary EDCR and one patient with revision EDCR with improving the result of surgery as presented in table [4].

Chronic sinusitis was present in 3 patients during the primary EDCR, and FESS was done without affection the result of surgery as presented in the table [4].

The average time of stent removal within an average 4-34 weeks where the stent was removed under topical anesthesia in primary EDCR with Mean \pm SD 11.31 \pm 5.20 and EDCR 7.00 \pm 1.73 in revision operations as shown in table [5].

Table [1]: Comparison between the success and failure groups regarding age, sex and the type of operation

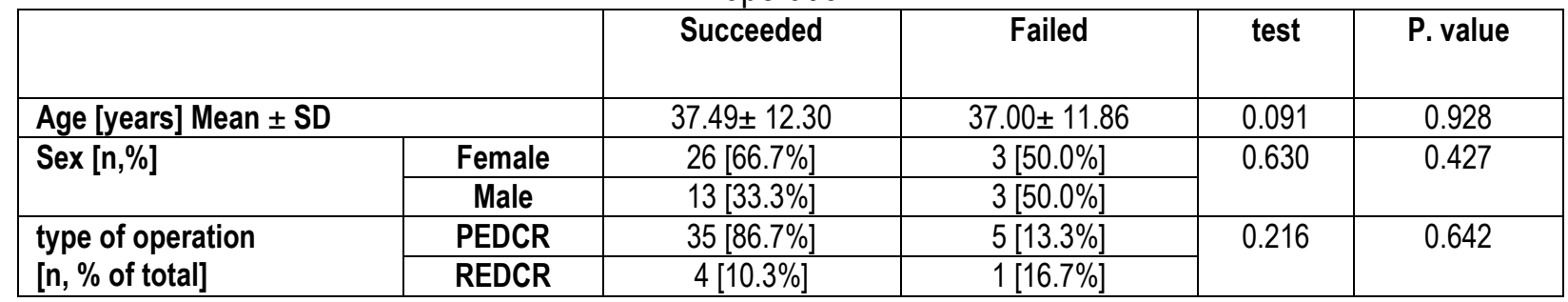

SD: standard deviation; PEDCR: primary endoscopic dacryocystorhinostomy; REDCR: Revision endoscopic dacryocystorhinostomy.

Table [2]: Comparison between the PEDCR and REDCR regarding the incidence of both minor and major intra and postoperative complications

\begin{tabular}{|c|c|c|c|c|c|}
\hline & PEDCR & REDCR & $\mathrm{X}^{2}$ & P.value \\
\hline \multirow{7}{*}{$\begin{array}{l}\text { Minor intra and } \\
\text { postoperative complications }\end{array}$} & Eye and check bruises & $3[7.7 \%]$ & $0[0.0 \%]$ & \multirow[t]{7}{*}{30.84} & \multirow[t]{7}{*}{$<0.001^{*}$} \\
\hline & Eye and check bruises and stent fell out & $0[0.0 \%]$ & $1[16.7 \%]$ & & \\
\hline & Intra nasal synechia & $1[2.6 \%]$ & $2[33.3 \%]$ & & \\
\hline & Nostril burn & $2[5.1 \%]$ & $0[0.0 \%]$ & & \\
\hline & Nostril burn and eye and check bruises & $2[5.1 \%]$ & $0[0.0 \%]$ & & \\
\hline & stent fallen out and inra nasal synechia & $0[0.0 \%]$ & $1[16.7 \%]$ & & \\
\hline & stent fallen out and intra nasal synnechia & $0[0.0 \%]$ & $1[16.7 \%]$ & & \\
\hline \multirow{2}{*}{$\begin{array}{l}\text { Major intra and } \\
\text { postoperative complication }\end{array}$} & No & $38[97.4 \%]$ & $6[100.0 \%]$ & \multirow[t]{2}{*}{0.157} & \multirow[t]{2}{*}{0.692} \\
\hline & Orbital penetration, with exposure of the orbital fat. & $1[2.6 \%]$ & $0[0.0 \%]$ & & \\
\hline
\end{tabular}

Table [3]: The cause of failure in revision EDCR.

\begin{tabular}{|c|c|c|c|c|}
\hline & Success & Failed & $\mathrm{X}^{2}$ & P. value \\
\hline No. & $39[100.0 \%]$ & $0[0.0 \%]$ & \multirow[t]{7}{*}{45.00} & \multirow[t]{7}{*}{$<0.001^{*}$} \\
\hline Failure in locating the lacrimal sac & $0[0.0 \%]$ & $1[16.7 \%]$ & & \\
\hline High deviated septum,granulation tissue, fibrosis and synechia & $0[0.0 \%]$ & $1[16.7 \%]$ & & \\
\hline Insufficient opening the lacrimal sac & $0[0.0 \%]$ & $1[16.7 \%]$ & & \\
\hline Insufficient osteotomy and neo bone osteogenesis & $0[0.0 \%]$ & $1[16.7 \%]$ & & \\
\hline Intra-nasal synechia and neo bone osteo genesis & $0[0.0 \%]$ & $1[16.7 \%]$ & & \\
\hline Neo bone osteogenesis & $0[0.0 \%]$ & $1[16.7 \%]$ & & \\
\hline
\end{tabular}

Table [4]: The rate of septoplasty and FESS in PEDCR and REDCR.

\begin{tabular}{|c|c|c|c|c|c|}
\hline \multicolumn{2}{|c|}{} & PEDCR & REDCR & X2 & P. value \\
\hline \multirow{2}{*}{ Septoplasty } & No & $34[87.2 \%]$ & $5[83.3 \%]$ & 0.067 & 0.796 \\
\cline { 2 - 5 } & Septoplasty & $5[12.8 \%]$ & $1[16.7 \%]$ & & \\
\hline Functional endoscopic sinus surgery & FESS & $3[7.7 \%]$ & $0[0.0 \%]$ & \multirow{2}{*}{0.495} & \multirow{2}{*}{0.482} \\
\cline { 2 - 5 } & No FESS & $36[92.3 \%]$ & $6[100.0 \%]$ & & \\
\hline
\end{tabular}

FESS: Functional endoscopic sinus surgery

Table [5]: Removal of the stent [per weeks] in primary and revision EDCR.

\begin{tabular}{|l|c|c|c|c|}
\hline & PEDCR & Revision EDCR & $\mathbf{t}$.test & P. value \\
\hline Time of stent fallen out and removed [weeks] & $11.31 \pm 5.20$ & $7.00 \pm 1.73$ & 1.414 & 0.165 \\
\hline
\end{tabular}




\section{DISCUSSION}

The current work results revealed that the rate of success in PEDC was $86.7 \%$ and $80 \%$ in REDCR compared with the study done by Peng et al., who showed the success rate was $92.7 \%$ who use the lacrimal and nasal mucosal flap in endoscopic dacryocystorhinostomyl121. Another study done by Orsolini et al. showed that the success rate was $94 \%$ in stent placement versus $90.4 \%$ without stent placement ${ }^{[13]}$. The rate of minor complications was $28.8 \%$. The intranasal synechiae was the most frequent minor complication; it was treated conservatively in primary cases and needs intervention by cutting the adhesion and removing synechia in revision cases. The second most frequent minor complications are stent falling out and eye and check brusies where eye and check brusies are treated conservative while if the stent fell out before the tract is made, the patient was needed revision surgery, and if it fell after the tract is made, it removed endoscopic ally in ear, nose, and throat [ENT] office. The less frequent complications are nostril burn and was treated conservative. Only one major complication was occurred in this study in two patients in the form of orbital penetration with exposure of orbital fat and was managed intra operative without any sequelae. A study was done by Lehmann et al who showed $20 \%$ postoperative complications, and other authors, as Durvasula et al. showed [20\%], and Lester et al. showed [19\%] $]^{114-161}$. Germany Horn et al. showed in their study that minor complications rate $10 \%[17]$. Orsolini et al concluded that the most frequent minor complications were stent extrusion ,false passage and granulation tissue formation with intra nasal synechia ${ }^{[13]}$. Continuous fluid flow and epithelial anastomosis are necessary for patency of surgical rhino -stoma, and this is done through silicone tube placement ${ }^{1181}$. In our study, the average of silicon tube fallen out and removed is from 4-34 weeks with the mean is $11.31 \pm 5.20$ in PEDCR and $7 \pm 1.73$ in REDCR.

Kong et al. recommended removing the silicon stent before eight weeks to avoid granulation tissue formation ${ }^{[19]}$. Boush et al. observed the relationship between the silicon tube retention and the success rate ${ }^{[201}$. One of the most challenges in endoscopic $D C R$ is the removal of the bone over the lacrimal sac because of the narrow confine of the sac, and meticulous care is needed to avoid injury by the powered drill. In this study, the most frequent cause of failure of primary and revision EDCR is scarring of the ostium by neo-bone osteogenesis, failure to locate the lacrimal sac, intra nasal synechia, and associated deviated nasal septum, which is corrected in the revision surgery. Five cases of 40 PEDCR were failed; one case of five cases of the revision endoscopic DCR is failed. Prakash et al. concluded in their study, failure reported in two endoscopic sinus surgeries from 37 operations and said the cause of failure is extensive granulation tissue in one patient and chronic canaliculitis in the other [21]. The most important cause of surgical failure is scarring of the ostium and difficulty in localization of the ostiumm ${ }^{[19]}$. Metson et al. also concluded re-closure of the the ostium for four endoscopic revisions from 5 failed revision endoscopic DCR ${ }^{[10]}$. On the contrary, Boush et al. showed five successes from 6 patients in revision EDCR ${ }^{[20]}$.

Conclusion: we could conclude that the endonasal endoscopic DCR is the best treatment for primary acquired nasolacrimal duct obstruction for experienced surgeons compared with external DCR as endoscopic DCR has many advantages as less intraoperative bleeding, shorter operating time, better cosmoses [no external scar], preservation of the lacrimal pump mechanism of orbicularis oculi muscle and high success rate.

Financial and Non-financial Relationships and Activities of Interest

$$
\text { None }
$$

\section{REFERENCES}

1.Ullrich K, Malhotra R, Patel BC. Dacryocystorhinostomy. In: StatPearls. Treasure Island [FL]: StatPearls Publishing; 2020 Aug 10 .http://europepmc.org/ abstract/ MED/22529662.

2. Raghuwanshi SK, Raghuwanshi S, Agarwal M, Batni G. Primary Endonasal DCR Without Stent: Our Experience and Case Series Analysis. Indian J Otolaryngol Head Neck Surg. 2015 Sep;67[3]:271274. doi:10.1007/s12070-015-0867. 
3.Lee S, Yen MT. Laser-assisted dacryocystorhinostomy: a viable treatment option? Curr Opin Ophthalmol. 2011; 22[5]:413-8. doi: 10.1097/ICU.0b013e32834994c8.

4.Önerci M. Dacryocystorhinostomy; Diagnosis and treatment of nasolacrimal canal obstructions. Rhinology. 2002 Jan;40[2]:49. PMID: 12091994

5. Ben Simon GJ, Joseph J, Lee S, Schwarcz RM, McCann JD, Goldberg RA. External versus endoscopic dacryocystorhinostomy for acquired nasolacrimal duct obstruction in a tertiary referral center. Ophthalmol. 2005; 112 [8]: 1463-8. doi: 10.1016/j.ophtha.2005. 03.015 .

6. Tsirbas A, Davis G, Wormald PJ. Mechanical endonasal dacryocystorhinostomy versus external dacryocystorhinostomy. Ophthal Plast Reconstr Surg. 2004: [20]: 50-56. doi: 10.1097/01.IOP.0000103006.49679.23.

7. Yigit O, Samancioglu M, Taskin U, Ceylan S, Eltutar K, Yener M. External and endoscopic dacryocystorhinostomy in chronic dacryocystitis: Comparison of results. Eur Arch Otorhinolaryngol 2007; 264:879-885. doi: 10.1007/ s00405-007-0286-0.

8. Wormald PJ. Powered endoscopic dacryocystorhinostomy. Laryngoscope 2002; [112]:69-72. doi: 10. 1097/00005537-200201000-00013.

9. Tsirbas A, Wormald PJ. Mechanical endonasal dacryocystorhinostomy with mucosal flaps. Am J Ophthalmol 2003; 135:76-83. doi:10.1136/bjo.87.1.43.

10. Metson R, Woog JJ, Puliafito CA. Holmium-YAG endonasal laser dacryocystorhinostomy. Am J Ophthalmol 1993;116:1-10. doi:10.1016/S0002-939 $4[14] 71736-2$.

11.Gurler B, San I. Long-term follow-up outcomes of nonlaser intranasal endoscopic dacryocystorhinostomy: how suitable and useful are conventional surgical instruments Eur J Ophthalmol. 2004 Nov-Dec; 14[6]: 453-60. doi: 10.1016/s0002-9394[02]01830-5.

12-Peng W, Tan B, Wang $Y$, Wang $H$, Wang Z, Liang $X$. A Modified Preserved Nasal and Lacrimal Flap Technique in Endoscopic Dacryocystorhinostomy. Sci Rep. 2017; 7 [1]: 6809. doi: 10.1038/s41598-01707364-9.
13- Orsolini MJ, Schellini SA, Souza Meneguim RLF, Catâneo AJM. Success of endoscopic dacryocystorhinostomy with or without stents: systematic review and meta-analysis. Orbit. 2020; 39[6]:258-265. doi: 10.1080/01676830.2019.1677726.

14-Lehmann $A E$, Scangas GA, Jafari A, Banks CG, Fullerton $\mathrm{ZH}$, Metson R. Predictors of long-term success and failure in primary and revision endoscopic dacryocystorhinostomy. Int Forum Allergy Rhinol. 2020 Mar;10[3]:374-380. doi: 10.1002/alr.22483.

15. Durvasula VSP, Gatland DJ. Endoscopic dacrocystorhinostomy: long-term results and evolution of surgical technique. J Laryngol Otol. 2004:118:628-632. doi: 10.1258/0022215041917835

16. Lester SE, Robson AK, Bearn M. Endoscopic 'cold steel' versus laser dacryocystorhinostomy: completing the audit cycle. J Laryngol Otol. 2008 Sep;122[9]:924-7. doi: 10.1017/S0022215107001363.

17.Horn IS, Tittmann M, Fischer M, Otto M, Dietz A, Mozet C. Endonasal nasolacrimal duct surgery: a comparative study of two techniques. Eur Arch Otorhinolaryngol. 2014 Jul;271[3]1923-31.doi: 10. 1007/ s00405-013-2774-8.

18.Woog, JJ, Metson, R, Puliafito, CA. Holmium: YAG endonasal laser dacryocystorhinostomy Am J Ophthalmol 1993 Jul;116:1-10. doi:10.1016/S00029394[14]71736-2.

19. Kong, YT, Kim, TI, Byung, WK. A report of 131 cases of endoscopic laser lacrimal surgery. Ophthalmology 1994; 101: 1793-800. doi:org/10.1016/S0161-6420. 31100-6.

20. Boush, GA, Bradley, NL, Dortzbach, RK. Results of endonasal laser-assisted dacryocystorhinostomy Ophthalmology $1994 ; 101: 955-9$. doi:10.1016/S01616420.31231-0.

21. Prakash MD, Viswanatha B, Rasika R. Powered Endoscopic Endonasal Dacryocystorhinostomy with Mucosal Flaps and Trimming of Anterior End of Middle Turbinate. Indian J Otolaryngol Head Neck Surg. 2015 Dec; 6.[4]:333-337. doi:10.1007/s12070-014-0807-2 


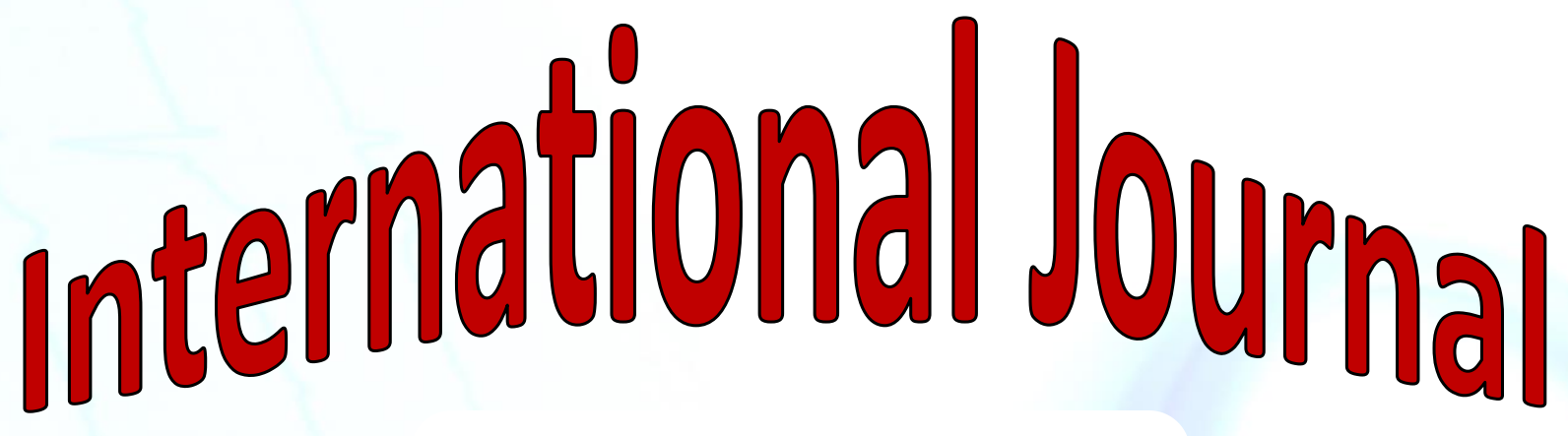

https://ijma.journals.ekb.eg/

Print ISSN: 2636-4174

Online ISSN: 2682-3780

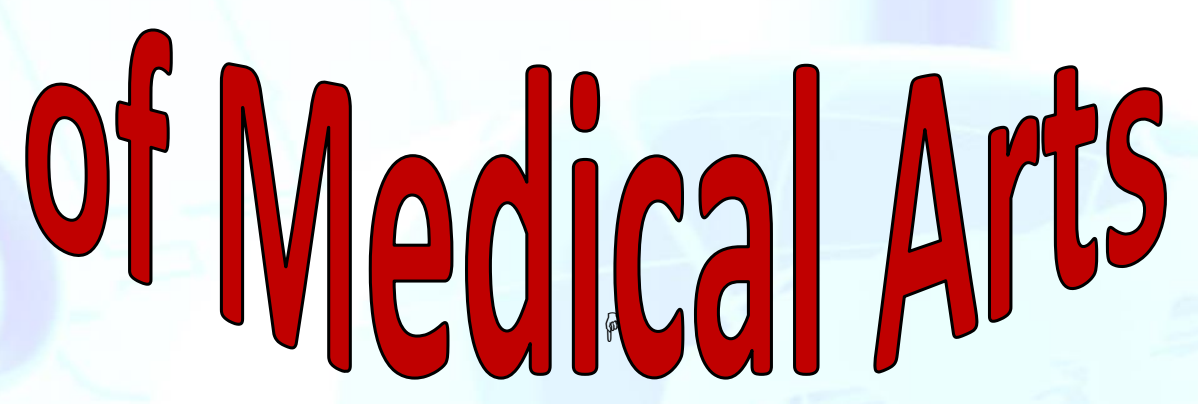

